\title{
ESTÁGIOS OBRIGATÓRIOS NO CURSO DE CIÊNCIAS SOCIAIS: REFLEXÕES ACERCA DA FORMAÇÃO DOCENTE
}

\author{
PRÁCTICAS OBLIGATORIAS EM LOS CURSOS DE CIENCIAS SOCIALES: \\ REFLEXIONES SOBRE LA FORMACIÓN DOCENTE
}

\section{MANDATORY INTERNSHIPS IN THE SOCIAL SCIENCES COURSES: REFLECTIONS ON TEACHING EDUCATION}

\author{
Maria Luzia Silva MARIANO ${ }^{1}$ \\ Sandra Aparecida Pires FRANCO ${ }^{2}$
}

RESUMO: A disciplina de Sociologia, por apresentar um caráter crítico e reflexivo, pode proporcionar aos alunos o desenvolvimento de elementos essenciais e indispensáveis à sua formação cidadã. $O$ professor de Sociologia tem papel fundamental nessa formação. O presente estudo objetivou refletir acerca da realização dos estágios obrigatórios do curso de Ciências Sociais de uma Universidade Pública no sul do estado de Minas Gerais. As reflexões são feitas à luz dos pressupostos teóricos materialista-histórico e dialético e da teoria histórico-cultural (e também com base em documentos oficiais voltados à educação nacional). Os desafios encontrados pelos licenciandos em questão são muitos, desde a infraestrutura precária das escolas públicas até a enorme falta de interesse e indisciplina dos alunos durante as aulas.

PALAVRAS-CHAVE: Ciências sociais. Ensino. Estágio obrigatório. Formação docente.

RESUMEN: La disciplina de Sociología, por presentar un carácter crítico y reflexivo, proporciona a los alumnos el desarrollo de elementos esenciales e indispensables para su formación ciudadana. El profesor de Sociología tiene un papel fundamental en esta formación. Este estudio reflexiona sobre la realización de las pasantías obligatorias del curso de Ciencias Sociales de una Universidad pública en el sur del Estado de Minas Gerais, basándose en los presupuestos teóricos del Materialismo Histórico y Dialéctico y de la Teoría Histórico-Cultural (y también con base en documentos oficiales de la educación nacional). Los desafíos encontrados por los licenciados en cuestión van desde la infraestructura precaria de las escuelas públicas hasta la enorme falta de interés e indisciplina de los alumnos durante las clases.

PALABRAS CLAVE: Ciencias sociales. Enseñanza. Prácticas obligatórias. Formación docente.

${ }^{1}$ Universidade Estadual de Londrina (UEL), Londrina - Brasil. Doutoranda em Educação. Programa de Pós-graduação em Educação da Universidade Estadual de Londrina. E-mail: malumariano@yahoo.com.br ${ }^{2}$ Universidade Estadual de Londrina (UEL), Londrina - Brasil. Pós-Doc em Educação. Programa de PósGraduação em Educação da Universidade Estadual de Londrina. E-mail: sandrafranco26@ hotmail.com

RIAEE - Revista Ibero-Americana de Estudos em Educação, Araraquara, v.12, n.4, p. 2044-2057, out./dez. 2017. 
ABSTRACT: Sociology, for being critical and reflective, can provide to students essential and indispensable elements to their citizenship education. The professor of Sociology plays a fundamental role in the formation of these young citizens. With such issues in mind, the present study aims to reflect on the achievement of the required internships in the Social Sciences Courses of a public university in the southern state of Minas Gerais. The reflections were made based on the theoretical assumptions of Historical and Dialectical Materialism and Historical-Cultural Theory (and also based on official of National Education). The challenges faced by undergraduates in Social Sciences are many, from the poor infrastructure of public schools to the huge lack of interest and lack of discipline of students during class.

KEYWORDS: Social Sciences. Teaching. Mandatory Internships. Teaching education.

\section{Introdução}

É a maneira como cada sociedade produz o seu modo de vida material que vai determinar, dentre outras questões, a forma de transmissão das ideias e dos conhecimentos. $\mathrm{Na}$ sociedade atual, a educação pode ser concebida como meio fundamental para a transformação da realidade que está posta. Então, é possível admitir que o significado da educação seja o de fazer com que os indivíduos possam viver positivamente à altura das condições sociais que se encontram historicamente em transformação. (LOMBARDI, 2012; MÉSZÁROS, 2008).

No entanto, não é essa educação capaz de transformar a realidade social que se percebe no âmbito educacional. De acordo com Mészáros (2008), na sociedade capitalista, a educação reproduz os interesses classistas de um grupo dominante, sendo empregada apenas para a manutenção da hegemonia estabelecida. Sendo assim, a escola teria o papel de prosseguir e reafirmar a lógica de determinismos sociais impostos pelas elites ou grupos dominantes.

Ao olhar para o percurso percorrido pela educação no Brasil, é possível perceber grande demora para o estabelecimento de leis específicas que regessem a Educação Básica. Como colônia de Portugal, como uma República ou sob forte regime ditatorial, o sistema educacional não figurou de forma prioritária nas diferentes administrações pelas quais o país passou. A demora no estabelecimento das leis que deveriam reger a educação nacional causou grandes retrocessos, que ainda podem ser sentidos na esfera educacional. (MARIANO, 2015).

Apesar da redemocratização do Brasil ter se dado em 1985, após 20 anos de ditadura militar, foi somente em 20 de dezembro de 1996 que foi promulgada a nova Lei

RIAEE - Revista Ibero-Americana de Estudos em Educação, Araraquara, v.12, n.4, p. 2044-2057, out./dez. 2017. 
de Diretrizes e Bases da Educação Nacional (LDBEN) (nº 9.394). Mesmo com a demora em seu estabelecimento, é possível admitir que a nova LDBEN trouxe mudanças significativas para o ensino brasileiro. Na lei há o evitar do caráter tecnicista que a Educação assumiu na época da ditadura, passando a priorizar a formação dos estudantes como um todo (MARIANO, 2015).

A educação escolar foi dividida em Educação Básica, sendo composta pelas etapas de: Ensino Infantil, Ensino Fundamental (oito anos) e Ensino Médio (três anos) e Ensino Superior. O Ensino Fundamental tornou-se obrigatório dos sete aos quatorze anos, a carga horária anual de horas-aula passou de 667 horas para 800 horas, devendo ser divididas em no mínimo duzentos dias letivos, excetuando o período de exames finais quando necessário. Também ficou estabelecido a valorização dos professores e a criação de instrumentos que diminuíssem os índices de repetência e defasagem escolar. (GONÇALVES, 2011).

O Ensino Médio aparece especificamente na sessão IV do capítulo II da LDBEN 9.394/96. No artigo 35, consta que essa etapa do ensino promove a consolidação das etapas anteriores, possibilitando a continuação dos estudos dos alunos e também a sua formação básica para o trabalho e exercício da cidadania. Esse artigo prevê o desenvolvimento do pensamento crítico de cada educando, e que nos conteúdos a serem ensinados se relacione a teoria com a prática. No artigo 36, consta que ao final do curso os alunos devem apresentar o domínio da Língua Portuguesa e conhecimentos de Filosofia e Sociologia necessários ao exercício da cidadania. (BRASIL, 1996).

Ainda não foi nesse momento que as disciplinas de Filosofia e Sociologia voltaram a fazer parte de forma definitiva e obrigatória do currículo da Educação Básica. $\mathrm{O}$ artigo 36 deu margem para outra interpretação, a de que as escolas realizassem um tratamento interdisciplinar e contextualizassem temas pertinentes à formação e ao exercício da cidadania dos alunos. Essa possibilidade seria o suficiente para que esses educandos tivessem acesso aos conteúdos pertinentes à Sociologia e à Filosofia. Sob tal perspectiva, ter o conhecimento dessas disciplinas não significaria incluí-las na grade curricular do Ensino Médio, bastava que um professor de Matemática, por exemplo, discutisse com seus alunos a porcentagem de desemprego no país, que ele estaria trabalhando a Matemática e a Sociologia respectivamente.

Foi somente com a promulgação da Lei 11.684/2008, que o inciso III do artigo 36 foi revogado, e passou a valer então o inciso IV, que estabeleceu a obrigatoriedade das duas disciplinas em todas as séries do Ensino Médio. É imprescindível que se tenha em 
mente que o Ensino Médio é a etapa final da Educação Básica, uma vez que essa etapa contém elementos indispensáveis para a formação do cidadão a fim de que este aluno exerça a sua cidadania sob perspectivas sociais, políticas e extensivas às suas relações de trabalho. Para tanto, foram criados os Parâmetros Curriculares Nacionais (PCN'S), que estabelecem os conteúdos comuns a serem ensinados nas disciplinas, respeitando as particularidades de cada região do território nacional. (CARVALHO, 2004).

Cada etapa da Educação Básica conta com documentos específicos para as séries que nela são englobadas. A publicação de 2000 dos Parâmetros Curriculares Nacionais do Ensino Médio (PCNEM) foi dividida em quatro partes, sendo a primeira parte referente às bases legais do documento, enquanto as outras três apresentam o agrupamento em três grandes áreas das disciplinas que devem ser ministradas na etapa final da Educação Básica. O documento logo no início esclarece que as grandes áreas têm por objetivo organizar e articular as disciplinas que compartilhem objetos de estudos, sem que isso elimine alguma ou dilua seu conteúdo. (BRASIL, 2000).

A disciplina de Sociologia é parte integrante de área denominada Ciências Humanas e suas Tecnologias, juntamente com as disciplinas de Filosofia, História e Geografia. Ainda divididos em três áreas de conhecimento, em 2007, os PCNEM's passam a ser designados por PCNEM+ após algumas reformulações, como por exemplo, a sugestão de eixos temáticos a serem trabalhados pelos professores. (BRASIL, 2007). Esses documentos devem servir como fontes complementares de apoio ao desenvolvimento do conteúdo e não algo imposto.

A Sociologia, apesar de ser uma ciência relativamente recente, apresenta um leque muito grande de conteúdos que podem ser trabalhados durante as aulas. O professor pode trabalhar conceitos de cidadania, trabalho, sociedade e cultura, por exemplo. Dentro desses conceitos outras temáticas também se fazem pertinentes, ou seja, o professor ao trabalhar sociedade com os seus alunos também precisa desenvolver temas como os modos de produção, desigualdades sociais, estratificação social, classes sociais, entre outros. Essa questão se dá também aos outros temas que podem ser desenvolvidos, pois a Sociologia é uma ciência ampla e complexa, que abrange temas que permeiam questões sociais, políticas, econômicas, culturais e religiosas.

No estado de Minas Gerais, especificamente, os alunos têm apenas uma aula de 50 minutos por semana da disciplina a partir do $1^{\circ}$ ano do Ensino Médio. A carga horária é extremamente reduzida para que se desenvolva uma quantidade tão grande de conteúdos teóricos. De acordo com Carvalho (2004), a disciplina de Sociologia demorou a fazer 
parte de forma definitiva do currículo obrigatório da Educação Básica, prejudicando a sua tradição entre as disciplinas e o seu desenvolvimento.

A Sociologia é uma disciplina crítica e reflexiva, que quando ministrada de forma plena, pode proporcionar aos alunos o desenvolvimento do seu senso crítico, característica essa necessária para que o aluno alcance o seu pleno desenvolvimento humano e social. O professor é quem figura como esse agente transmissor e promove o uso da pedagogia dialética em suas aulas. No entanto, ministrar conteúdos de forma completa em uma reduzida carga-horária torna-se impossível. Dessa forma, o professor não consegue proporcionar aos seus alunos a formação omnilateral que é desejável para o seu pleno desenvolvimento, (FRANCO \& MARIANO, 2015).

Para que o professor seja capaz de proporcionar essa formação omnilateral aos seus alunos, é necessário que ele também tenha tido a mesma formação. De acordo com Barros e Franco (2010), o ser omnilateral é aquele que compreende e assimila as situações que o cerca, valorizando o ser humano e o seu desenvolvimento. Trata-se de um ser humano plenamente desenvolvido e consciente de suas diversas possibilidades. Para isso, é necessário também que o professor trabalhe e desenvolva os conteúdos escolares de modo que esses se aproximem da realidade e do interesse dos seus alunos.

Os conteúdos e as aulas são encarados como vagos e cansativos, pois na maioria das vezes são muito distantes da realidade desses alunos. Os alunos não entendem o motivo de estudar aquele conteúdo, não os considerando significativos para a sua vivência na realidade social. Segundo Vigotski (2010), para que o ensino seja eficaz, o aluno precisa perceber a relação entre o seu conhecimento prévio e o conhecimento que a ele está sendo apresentado na escola. Ao fazer essa relação, o aluno deixa a esfera menos elaborada, passa a compreender e ter domínio do que o cerca e, consequentemente, atinge a esfera mais elaborada do saber.

Portanto, professor e aluno precisam encontrar uma maneira de tornar os conteúdos escolares mais interessantes e envolventes, aliando a teoria ao que é perceptível no cotidiano de cada um. Com isso, o professor pode buscar métodos didáticos que fujam dos que convencionalmente são utilizados na sala de aula e que se apresentem de forma mais atrativa aos alunos, a fim de que a sua capacidade reflexiva seja desenvolvida em detrimento de conhecer a matéria apenas para realizar uma atividade ou ter sucesso em algum teste. (GASPARIN, 2012).

Sendo assim, o objetivo do presente estudo foi o de refletir acerca dos conteúdos e métodos utilizados no ensino da disciplina de Sociologia e também das dificuldades 
encontradas pelos professores em desenvolver os conteúdos pertinentes à disciplina a partir das experiências vivenciadas ao longo dos estágios obrigatórios do curso de Ciências Sociais.

\section{Metodologia}

As análises e reflexões contidas no presente estudo são fruto de observações sistemáticas ${ }^{3}$ realizadas durante os quatro estágios obrigatórios do curso de Licenciatura em Ciências Sociais de uma Universidade Pública no sul do estado de Minas Gerais. Os estágios foram feitos em três escolas diferentes, uma pertencente à Rede Púbica Estadual de ensino e as outras duas pertencentes à Rede Particular de ensino.

O estágio obrigatório é parte essencial à formação acadêmica do licenciando. Trata-se de parte dos processos de ensino e de aprendizagem, que buscam a integração entre teoria e prática. Especificamente na modalidade de Licenciatura do curso de Ciências Sociais da Universidade supracitada, os licenciados cumprem uma carga horária total de 405 horas, que são subdivididas em quatro semestres letivos. As cargas horárias de cada semestre não são cumpridas integralmente na instituição de ensino, elas se subdividem em leituras, reuniões com o coordenador do estágio, elaboração do plano de ensino e elaboração do relatório final. Cada estágio apresenta um objetivo específico diferente, organizados de modo que todo o contexto escolar seja experienciado pelo discente.

No estágio supervisionado I, o educando tem como objetivo conhecer a escola, sua estrutura, organização e funcionamento como instituição de ensino. O objetivo do estágio II é conhecer o currículo escolar definido e praticado pelos professores de Ciências Sociais e apreender as condições e trajetórias do trabalho docente em sala de aula. Ao cursar o estágio III, o aluno procura conhecer e apreender as metodologias de ensino e os processos de ensino e de aprendizagem praticados pelos professores de Ciências Sociais; iniciar o processo de coparticipação e regência, visando a elaboração, execução e avaliação de atividades didáticas. Por fim, o objetivo do último estágio supervisionado é conhecer, elaborar, desenvolver e avaliar junto aos professores atividades relacionadas ao ensino de Ciências Sociais como parte integrante de processos de regência das atividades didáticas. (UNIFAL-MG, 2011).

\footnotetext{
${ }^{3}$ As observações foram registradas em diários de campo.
} 
A partir das observações foi possível identificar grande desinteresse dos alunos pela disciplina e um alto índice de indisciplina durante as aulas. A presença dos estagiários na escola e nas salas de aula, na grande maioria das vezes, não fez com que os alunos se portassem de maneira diferente. Ao contrário do que foi possível perceber em relação aos professores, que se mostravam desconfortáveis com os olhares atentos.

Nas três escolas em que o estágio foi realizado, foram desenvolvidas atividades com as turmas do professor regente da disciplina. Todas as escolas contavam com as três turmas do Ensino Médio e em cada uma foi possível perceber a diferença dos alunos na recepção e aceitação com as atividades propostas. Vale ressaltar que todas as atividades foram planejadas com base nos conteúdos que os alunos devem se apropriar ao final do Ensino Médio e foram aprovados e acompanhados pelo professor responsável da escola em questão.

\section{Resultados e discussão}

Com o intuito de manter em sigilo a identidade das escolas em que os estágios foram realizados e para que elas possam ser diferenciadas entre si, as mesmas serão denominadas por E (escola pública) e P1 e P2 (colégios particulares). Os dois primeiros estágios do curso foram realizados na Escola E, o estágio III na Escola P1 e o estágio IV na Escola P2. Inúmeras diferenças foram percebidas ao comparar as duas redes de ensino, como a estrutura física das escolas e a quantidade de aulas que os alunos têm por dia e, consequentemente, por semana. Foi possível perceber também a diferença no material didático utilizado: as escolas particulares utilizam apostilas que são atualizadas anualmente, as escolas públicas utilizam os mesmos livros por alguns anos.

Mesmo não sendo a questão estrutural das escolas, o ponto essencial para as reflexões efetuadas neste estudo são algumas diferenças importantes citadas, pois indicam possibilidades de comparações. As escolas particulares apresentam, por exemplo, pelo menos uma sala específica com sistema multimídia independente, não sendo necessário montar e desmontar o equipamento a cada utilização. Nas escolas públicas, apenas uma delas apresenta uma sala com esse sistema e é, consideravelmente, precário se comparado ao das escolas particulares.

É significativo o tempo que se leva para montar e desmontar a aparelhagem para que esta seja utilizada durante a aula, por isso uma sala onde os aparelhos sejam fixos é fundamental para a otimização do tempo da aula. Sem contar que apenas uma sala de 
multimídia para tantas turmas restringe o trabalho do professor, sendo necessário um agendamento prévio para a utilização de tais recursos.

Outro fato relevante é que a utilização dos aparelhos tecnológicos proporciona ao professor fugir do sistema tradicional de aulas (passar matéria no quadro, esperar os alunos copiarem e depois explicar), fazendo com que estas fiquem mais atrativas por meio da exibição de um filme ou mesmo a utilização para a exibição da matéria. O simples fato de fugir do convencional em muitas situações incita a participação e atenção dos alunos, diminuindo o índice de indisciplina durante as aulas.

Vale ressaltar também que as salas de aula das escolas particulares são mais amplas e arejadas, apresentando carteiras padronizadas e suficientes para o número de alunos na sala de aula; normalmente sobram carteiras vagas e o espaço entre uma carteira e outra não é pequeno. As salas de aula das escolas públicas são pequenas para o número de alunos, as carteiras não são padronizadas, sendo mal cuidadas e muitas vezes insuficientes para a quantidade de alunos em cada série.

Como o estágio I prevê apenas o primeiro contato com a estrutura escolar e seu funcionamento, o contato com os alunos e também com os professores não foi diretamente na sala de aula, mas de forma esporádica no pátio da escola, onde algumas conversas breves aconteceram. A escola foi observada como um todo, e, dessa forma, foi possível criar bases para desenvolver um trabalho de quem observa e de quem também participa do processo de escolarização. Nos outros três estágios obrigatórios do curso foram desenvolvidas atividades didáticas com algumas das turmas. É importante ressaltar que apesar do planejamento do estágio II não prever tal atividade por parte dos graduandos, essa demanda se mostrou necessária.

A recepção e aceitação das turmas e também dos professores bem como da equipe diretiva nas três escolas foi diferente. Na Escola E, a professora regente das turmas mostrou-se confortável com a presença dos estagiários, chegando a permitir que mais de um aluno a acompanhasse por aula, indo contra ao que a direção determinou em dado momento do período em que o estágio foi realizado; os alunos se mostraram indiferentes. Em movimento oposto, o corpo diretivo da escola não se mostrou muito aberto à presença externa, chegando inclusive a finalizar o período de estágio simplesmente com o seguinte aviso colado no portão da escola: ATENÇÃO: Estamos finalizando nossas atividades e por isso, o atendimento aos estagiários está encerrado nesse ano. Assinatura de documentação com a diretora apenas nos dias 5 e 6 de dezembro. Grata, A direção'. 
Na Escola P1, o contato inicial com a direção foi muito difícil de acontecer, mas após a autorização, o estágio se deu sem nenhum tipo de interferência. A professora e os alunos se mostraram desconfortáveis com a presença dos estagiários na escola. A própria professora em determinado momento explicou que prefere os estagiários com ela à frente da sala, pois quando estes estão sentados como os alunos, ela se sente desconfortável. No tocante aos alunos, a atenção que eles demonstraram ter nas aulas quando a professora estava à frente da turma não foi a mesma quando os estagiários propuseram a atividade didática e eles de certa forma se negaram a fazer o que foi proposto.

Na Escola P2, a coordenadora pedagógica foi extremamente solícita ao receber a documentação para o início do estágio, dizendo que a escola precisava da presença dos estagiários. O professor responsável pela disciplina de Sociologia também foi muito solícito, mostrando-se confortável com a presença dos estagiários ao observarem suas aulas e disponível ao ceder suas aulas para que os licenciandos regessem uma aula de elaboração deles com o seu auxílio. Os alunos fizeram a atividade avaliativa do projeto somente após o professor informar que os pontos do bimestre referente ao quesito participação seriam atribuídos após a conclusão das atividades dos estagiários.

O desenvolvimento dos estágios II, III e IV se deu da mesma maneira, primeiramente os licenciandos observaram as aulas e depois elaboraram um projeto para a regência das mesmas. A diferença se deu apenas na elaboração do projeto, pois na Escola E o tema trabalhado com todas as turmas foi visando a valorização e o respeito com o professor, uma vez que os alunos não demonstraram consideração nenhuma com a professora. O tema a ser trabalhado na Escola P1 foi determinado pela professora da disciplina e ministrado apenas aos alunos do $3^{\circ}$ ano. Na Escola P2, o tema pode ser escolhido livremente e foi trabalhado com as turmas do $1^{\circ}$ e $2^{\circ}$ ano, mas a atividade avaliativa foi aplicada só aos alunos do $1^{\circ}$ ano.

É importante ressaltar que em nenhuma das escolas, o professor regente da disciplina tinha formação específica em Sociologia ou em Ciências Sociais. Considerando o caminho que a disciplina de Sociologia percorreu até ser estabelecida como disciplina obrigatória da Educação Básica, há de se considerar as consequências negativas e os atrasos para sua afirmação como matéria que precisa chegar ao conhecimento dos estudantes. 
prejudicada a pesquisa nesta área, o desenvolvimento de metodologias adequadas, de textos didáticos sérios, de recursos didáticos tais como audiovisuais, entre outros. A formação de professor nessa área ficou empobrecida, diante da falta de perspectiva de atuação [...]. (CARVALHO, 2004, p. 80).

Outro ponto que precisa ser mencionado é o conteúdo trabalhado com os alunos durante as aulas de Sociologia. Na Escola E foi notório o fato da professora trabalhar o mesmo conteúdo nas três séries do Ensino Médio, fato esse que não ocorreu nas escolas P1 e P2. Na Escola P1, os professores recebem as apostilas com o conteúdo a ser trabalhado em cada bimestre com os alunos. Dessa forma, o conteúdo vem previamente separado para cada ano. Na Escola P2, as apostilas com o conteúdo também são disponibilizadas. No entanto, o professor faz a opção por não utilizá-las, para ter maior liberdade em trabalhar os assuntos clássicos e também as atualidades, sem ficar engessado com o determinado no material didático. Mesmo o professor não utilizando as apostilas do sistema de ensino, ele trabalhou assuntos diferentes em todas as séries.

Não é possível admitir que o mesmo conteúdo seja trabalhado em todos os anos do Ensino Médio sem uma prévia distinção. Supõe-se que o conhecimento e a capacidade de articulação de um aluno do $3^{\circ}$ ano do Ensino Médio são muito diferentes, até mesmo superiores, do que os de um aluno das séries anteriores, por isso a necessidade de que se trabalhe com conteúdos distintos com esses alunos. Apesar disso, em todas as aulas observadas da disciplina de Sociologia, foi possível verificar o cumprimento das designações contidas nos PCN'S e na LDBEN/96.

Dessa forma, no que diz respeito ao ensino da disciplina de Sociologia, é crucial admitir que os professores trabalharam os conteúdos científicos, mas apenas à luz de questões objetivas. Isso quer dizer que não foi proporcionado aos alunos a real reflexão do que lhes estava sendo transmitido, aconteceu apenas a mera reprodução de conceitos estabelecidos. Houve falta de que os docentes proporcionassem aos alunos reflexões concretas que se aproximassem da realidade vivenciada por esses eles. De acordo com Gasparin (2012), o que deve indicar a aprendizagem do aluno é o domínio que ele apresenta em relação ao conteúdo e a capacidade de utilizar esse conteúdo no seu cotidiano.

Gasparin (2012) afirma ainda que para que isso seja possível, professores e alunos devem perceber a importância teórico-prática dos conhecimentos escolares. É necessário que os alunos se interessem e se envolvam com o que está sendo ensinado. Nas três escolas foi possível perceber um alto índice de indisciplina durante as aulas, falta de 
concentração e também de participação. Os alunos da Escola E em sua grande maioria não se preocupavam em participar das aulas, enquanto os das Escolas P1 e P2 limitavamse a copiar os conteúdos e, esporadicamente, responder alguma questão proposta.

De acordo com Silva (2007), a falta de concentração e de atenção por parte dos alunos pode ser considerada como indisciplina, o que inviabiliza fortemente os processos de ensino e de aprendizagem. Mesmo que a incidência de conversas, a falta de participação ou o uso de fones de ouvido sejam maiores na Escola E, tais atitudes também são perceptíveis nas Escolas P1 e P2. Cabe, então, novamente, aos alunos e professores trabalharem juntos a fim de encontrar uma maneira de tornar o conteúdo mais atraente, mais dinâmico e também aplicável ao dia a dia de cada um (GASPARIN, 2012). Nesse sentido, é possível que o professor se desprenda dos métodos tradicionais e cansativos de transmissão do conhecimento e seja esse mediador entre o aluno e a realidade que o cerca.

Araújo, Bridi e Motim (2009) discutem algumas formas de propiciar ao aluno uma interação com temas do cotidiano que muitas vezes ficam apenas na observação do profissional da Sociologia como pesquisador. As autoras, entre outros temas, trazem à luz a discussão de elementos que possam ser utilizados no processo de ensino e aprendizado dos alunos do Ensino Médio para a compreensão de temas que fazem parte do dia a dia dos alunos, sendo o júri simulado um bom exemplo de atividade didática.

Para a realização de tal atividade, o professor precisaria trabalhar com seus alunos num processo de compreensão do tema e das diversas possibilidades acerca do assunto. Ao tratar de um tema em sala de aula com uma simulação do júri, o professor de Sociologia separaria a sala em grupos de argumentação: os alunos que fariam o discurso favorável, os que falariam contra o tema proposto e por fim os que fariam a avaliação. Para tanto, seria necessário um trabalho em conjunto dos alunos com o professor e entre os próprios alunos, a fim de se adquirir argumentos consistentes para o debate com os demais colegas.

$\mathrm{O}$ professor levaria a seus alunos as questões importantes para a leitura e compreensão de um tema, e com a ajuda do professor os alunos ao buscarem material e leituras estariam ampliando sua formação e aplicando os conhecimentos na sua realidade. Atividades como o júri simulado podem trazer aos alunos por meio de discussões a compreensão de conceitos trabalhados no universo sociológico. (ARAÚJO; BRIDI; MOTIM, 2009). 


\section{Considerações finais}

O contexto social, cultural e econômico em que a escola, seus alunos e professores estão inseridos são considerados aspectos essenciais para que se possa, mesmo que em pequena escala, analisar a qualidade do ensino ofertado na Rede Pública e na Rede Privada e o interesse dos alunos ao que lhes está sendo oferecido. Se observadas do âmbito estrutural, a diferença entre a Rede Pública de ensino e a Particular é enorme, como descrito anteriormente, porém se observadas pelo âmbito da sala de aula, a realidade destas chega a ser semelhante.

Os alunos têm grande dificuldade em se concentrar e em se manter em silêncio para que o professor explique como será a aula e o conteúdo a ser trabalhado. Mesmo que nas escolas particulares os professores consigam trabalhar de uma forma mais eficiente, muitas vezes quando questionados ou estimulados a participar da aula, os alunos se mostram alheios ao conteúdo que está sendo apresentado e demoram até que consigam voltar a se concentrar. É necessário admitir todo o contexto que envolve o aluno, independente da classe social a qual ele pertença, ou seja, o conjunto das influências por ele sofridas, em casa, na escola e nos demais ambientes, que possibilitam a explicação do fenômeno da indisciplina, da falta de concentração e também de interesse na sala de aula.

Apesar de todos os esforços para incluir a disciplina nas grades de ensino de todo o país como obrigatória, enquanto a Sociologia não for pensada como uma ciência indispensável para a formação dos alunos pelos próprios profissionais que por ela são responsáveis, será uma tarefa cada vez mais difícil transpor os muros que barram o seu desenvolvimento e consolidação. A Sociologia precisa deixar de ser concebida somente como mais uma disciplina a ser cumprida e ser tratada como uma ciência que além de se ocupar de objetos da natureza humana, é capaz de construir o indivíduo socialmente crítico.

Dessa forma, o grande desafio dos licenciandos em Ciências Sociais constitui-se em, conhecendo profundamente as raízes da Sociologia, traçar pontes entre as teorias e métodos deste universo de conhecimento que exerçam a função de conectar os saberes teóricos com a realidade e as vivências dos indivíduos da Educação Básica, sem deixar a profundidade dos estudos sociais e utilizando métodos pedagógicos atraentes e dinâmicos em sala de aula, para que os alunos percebam a importância e a aplicabilidade das Ciências Sociais em sua formação e em todo o seu percurso social e profissional.

RIAEE - Revista Ibero-Americana de Estudos em Educação, Araraquara, v.12, n.4, p. 2044-2057, out./dez. 2017. 
Para que o Ensino de Sociologia encontre êxito no Ensino Médio, é indispensável a percepção dos professores de que a disciplina, se trabalhada de forma plena, pode ser instrumento de mudanças na forma com que os alunos percebem o social, e isto ocorrendo é possível transformar ações coletivas que favoreçam o ambiente em que se vive.

\section{REFERÊNCIAS}

ARAUJO, S. M. de. BRIDI, M. A.; MOTIM, B. L. Ensinar e aprender Sociologia no Ensino Médio. São Paulo: Contexto, 2009.

BARROS, M. S. F.; FRANCO, S. A. P. O Caráter atual da Educação profissional: formação unilateral ou omnilateral do homem? In: CHAVES, M. SETOGUTI, R. I.; MORAES, S. P. G. de (Orgs.). A formação do professor e intervenções pedagógicas humanizadoras. 1. ed. Curitiba: Instituto Memória Editora, 2010.

BRASIL. Presidência da República. Lei no. 9.394 de 20 de dezembro de 1996. Lei de Diretrizes e Bases da Educação Nacional. Disponível em:

<http://portal.mec.gov.br/arquivos/pdf/ldb.pdf>. Acesso em: 20 jan. 13.

BRASIL. Presidência da República. Lei no $\mathbf{1 1 . 6 8 4}$ de 2 de junho de 2008. Estabelece as diretrizes e bases da educação nacional, para incluir a Filosofia e a Sociologia como disciplinas obrigatórias nos currículos do ensino médio. Disponível em:

<http://www.planalto.gov.br/ccivil_03/_Ato2007-2010/2008/Lei/L11684.htm>. Acesso em: 20 jan. 13.

BRASIL. Ministério da Educação. Secretaria de Educação média e Tecnológica. Parâmetros curriculares nacionais (ensino médio). Brasília. 2000. Disponível em: <http://portal.mec.gov.br/seb/arquivos/pdf/blegais.pdf>. Acesso em: 14 abr. 2016.

BRASIL. Ministério da Educação. Secretaria de Educação Básica. PCN + Ensino Médio: Ciências Humanas e suas Tecnologias. Brasília. 2007. Disponível em: <http://portal.mec.gov.br/seb/arquivos/pdf/CienciasHumanas.pdf >. Acesso em: 14 abr. 2016.

CARVALHO, L. M. G. de (Org.). Sociologia e ensino em debate: experiências e discussão de sociologia no ensino médio. Ijuí: Unijuí, 2004.

FRANCO, S. A. P.; MARIANO, M. L.S. As várias dimensões na trilogia Jogos Vorazes: uma aplicação prática para o ensino médio. Impulso, Brasil, 25, set. 2015. Disponível em: <https://www.metodista.br/revistas/revistasunimep/index.php/impulso/article/view/2394/1653>. Acesso em: 16 abr. 2016.

GASPARIN, J. L. Uma Didática para a Pedagogia Histórico-Crítica. 5. ed. Campinas: Autores Associados, 2012 (Coleção educadores contemporânea).

MARIANO, M. L. S. Qualidade Motivacional no Ensino Médio: estudo sobre relações com a maturidade e a escolha profissional. 2015. 110 f. Dissertação (Mestrado)

RIAEE - Revista Ibero-Americana de Estudos em Educação, Araraquara, v.12, n.4, p. 2044-2057, out./dez. 2017. 
- Curso de Educação - Centro de Educação, Comunicação e Artes - Universidade Estadual de Londrina, Londrina, 2015.

MÉSZÁROS, I. A Educação para além do capital. São Paulo. Editora Boitempo. 2008.

SILVA, L. C. da. Disciplina e indisciplina na aula: uma perspectiva sociológica. 2007. 284 f. Tese (Doutorado) - UFMG, Belo Horizonte, 2007.

UNIVERSIDADE FEDERAL DE ALFENAS (UNIFAL-MG). Projeto Pedagógico Curso de Ciências Sociais - Licenciatura. 2011. Disponível em: <http://www.unifalmg.edu.br/graduacao/system/files/imce/PPC\%20com\%20Resolu\%C3\%A7\%C3\%B5es $\% 20$ site\%20set-2015.pdf>. Acesso em: 13 abr. 2016

VIGOTSKI, L. S. Formação social da mente. São Paulo, SP: Martins Editora, 2010.

\section{Como referenciar este artigo}

MARIANO, Maria Luzia Silva.; FRANCO, Sandra Aparecida Pires. Estágios obrigatórios no curso de Ciências Sociais: reflexões acerca da formação docente. Revista Ibero-Americana de Estudos em Educação, Araraquara, v. 12, n. 4, p. 2044-2057, out./dez. 2017.2 Disponível em: <http://dx.doi.org/10.21723/riaee.v12.n4.out./dez.2017.8813>. E-ISSN: 1982-5587.

Submetido em: 26/07/2016

Revisões requeridas: 09/06/2017

Aprovado em: 27/07/2017 